\title{
Possibilidades Analíticas sobre o Desenvolvimento Rural a partir da Nova Economia Institucional Um Estudo de Caso na Vitivinicultura do Rio Grande do Sul
}

\author{
http://dx.doi.org/10.21527/2237-6453.2019.48.334-352
}

Recebido em: 20/4/2018

Aceito em: 20/3/2019

Claudio Vinicius Silva Farias, ${ }^{1}$ Leonardo Xavier da Silva²

\begin{abstract}
RESUMO
O presente artigo pretende apresentar-se como um ensaio teórico sobre o emprego dos principais conceitos da Nova Economia Institucional (NEI) para a compreensão do fenômeno do desenvolvimento rural, centrando a análise nas propostas de seu autor principal, Douglass North. Após uma ampla revisão, apresenta-se um modelo analítico que contemple as principais transformações ocorridas, nos ambientes organizacionais, tecnológicos, competitivos e institucionais, no âmbito da vitivinicultura da Serra Gaúcha. A partir de tais análises, um conceito de desenvolvimento rural sob a ótica institucional é proposto. O conceito busca entender o desenvolvimento rural de forma mais ampla do que apenas um olhar econômico sobre a produção em ambientes rurais. Considera-se que a proposta aqui apresentada poderá qualificar as análises empíricas, alcançando dimensões ainda pouco exploradas nos estudos do desenvolvimento rural, tais como a sua historicidade e suas configurações sociais e institucionais, que condicionam as intervenções dos atores no território, produzindo suas trajetórias de desenvolvimento.
\end{abstract}

Palavras-chave: Nova economia institucional. Desenvolvimento rural. Proposta metodológica.

\section{ANALYTICAL POSSIBILITIES FOR RURAL DEVELOPMENT FROM THE NEW INSTITUTIONAL ECONOMY: A CASE STUDY IN VITICULTURE IN THE STATE OF RIO GRANDE DO SUL}

\section{ABSTRACT}

This paper intends to present as a theoretical essay on the use of the main concepts of the New Institutional Economy (NIE) to understand the phenomenon of rural development, focusing the analysis on the proposals of its main author Douglass North. After an extensive review, we present an analytical model that contemplates the main transformations that took place, in the organizational, technological, competitive and institutional environments, in the viticultural sector of the state of Rio Grande do Sul. From these analyzes, a concept of rural development from the institutional perspective is proposed. The concept seeks to understand rural development more broadly than just an economic look at production in rural settings. It is considered that the proposal undertaken here may qualify the empirical analysis, reaching dimensions not yet explored in rural development studies, such as its historicity and its social and institutional configurations, which condition the interventions of the actors in the territory, producing their trajectories of development.

Keywords: New institutional economy. Rural development. Methodological proposal.

\footnotetext{
${ }^{1}$ Doutor em Desenvolvimento Rural pela Universidade Federal do Rio Grande do Sul (UFRGS). Professor do Instituto Federal de Educação, Ciência e Tecnologia do Rio Grande do Sul (IFRS). claudio.farias@poa.ifrs.edu.br

2 Doutor em Economia pela Universidade Federal do Rio Grande do Sul (UFRGS). Professor da Universidade Federal do Rio Grande do Sul (UFRGS). leonardo.xavier@ufrgs.br
} 
O presente artigo pretende realizar um debate sobre as possibilidades de emprego da Nova Economia Institucional (NEI) e seu ferramental analítico, para realização de estudos no campo do desenvolvimento rural. Na atualidade, há um considerável número de estudos que apresentam análises descritivas sobre a NEI e um número semeIhante de trabalhos que apontam críticas a esta abordagem. O que se pretende aqui é realizar uma discussão quanto ao método utilizado pela NEI, centrando a análise nas propostas de seu autor principal, Douglass North.

A obra de Douglass North é bastante ampla, podendo-se perceber que, ao longo dos anos, o programa de pesquisa por ele proposto sofreu algumas alterações. Neste artigo não se pretende realizar uma análise exaustiva do esquema teórico de Douglass North, tampouco da NEl. O que se deseja é justamente analisar as possibilidades analíticas e as construções metodológicas oriundas da NEI, que possam servir de base para uma discussão institucional sobre o desenvolvimento rural.

A NEI, na condição de esquema teórico particular da economia, não é homogênea. Isso porque seus autores abordam questões relativamente às instituições de maneira diversa, porém com um propósito comum, qual seja, a introdução das instituições nas análises econômicas. Também não há homogeneidade na conceituação do elemento central dessa abordagem, ou seja, o que vem a ser "instituição".

Théret (2003) classifica a NEI como o "institucionalismo da escolha racional", apontando três temáticas pertencentes a essa escola de pensamento:

a. teoria da firma e custos de transação (Coase e Williamson);

b. história econômica e mudança institucional (North e Matthews);

c. equilíbrio num contexto de interações estratégicas, teoria dos jogos (Schelling, Schotter e Shubik).

Em sintonia com a proposta da NEI, North sugere a discussão de questões referentes à história e às instituições a partir do instrumental teórico neoclássico. ${ }^{3} \mathrm{E}$ é sobre o ponto de vista metodológico que residem as maiores críticas relativas à NEI. Muitos, na tentativa de apresentarem suas críticas a esta abordagem, classificam-na como um mero desdobramento da Escola Neoclássica (CONCEIÇÃO, 2002; HODGSON, 1994; 2002; PEREIRA, 2012). ${ }^{4}$ Ocorre que North, apesar de um crítico dos economistas neoclássicos, utiliza-se de parte do instrumental dessa escola para sustentar suas propostas teóricas. A ideia de incorporar a história e as instituições na análise econômica fica evidente nas obras de North, bem como sua tentativa de modificar, em parte, a teoria neoclássica. Nesse propósito, o conteúdo principal a substituir é o pressuposto da racionalidade substantiva pelo da racionalidade limitada (com base no entendimento de Herbert Simon). Com a modificação do suposto de racionalidade, North tornou possível analisar a história e o desenvolvimento econômico nos limites do programa de pesquisa neoclássico, tratando as instituições a partir de uma lógica microeconômica.

\footnotetext{
3 Importante notar que muito embora o autor adote o arcabouço neoclássico como ponto de partida, North se posiciona como um crítico da economia neoclássica padrão, por ele denominado de modelo econômico neoclássico puro (NORTH, 1990, p. 12). O autor deixa claro essa posição em diversas de suas obras (NORTH; THOMAS, 1973; NORTH, 1990, 2005), bem como em sua Nobel Lecture - North (1993b).

${ }^{4}$ Uma crítica importante ao trabalho de North é aquela produzida por Chang (2004). Segundo este autor, North teria focado excessivamente a ideia de instituição como regra restritiva, não reconhecendo seu papel de habilitadora e constituinte da ação individual.
} 
Fica evidente que a NEI, apesar de receber contribuições da economia neoclássica, ${ }^{5}$ não se limita a tal, indo além em diversos pontos. A NEl abre espaços para testes empíricos e aplicações: um bom exemplo é o próprio conceito de instituições, em North, formulado a partir de uma teoria do procedimento humano e a teoria dos custos de transação.

A pergunta fundamental nesse artigo é: A NEI, na condição de programa de pesquisa, ${ }^{6}$ torna possível a compreensão do desenvolvimento rural? A resposta que este trabalho dá é sim, por dois motivos. Primeiramente, porque a NEl faz uso de um conjunto de conceitos, organizados de forma coerente, oferecendo um importante ferramental de análises e explicações de fatos sociais e econômicos (MÉNARD, 2001). Em geral, tais conceitos têm como cerne a maior relevância das transações em relação à produção, e que na organização dessas transações existem custos. Em segundo lugar, no marco analítico da NEI há prescrições metodológicas, a saber: a) busca pela construção de uma teoria; b) busca pela construção de modelos; c) busca pela mensuração dos resultados (AGUILAR FILHO, 2009).

O artigo, como ensaio teórico, encontra-se estruturado em três subseções, além desta introdução. Inicialmente é apresentado o programa de pesquisa da NEI, em especial a partir de uma análise das obras de North; nessa parte será possível perceber a postura de North com relação à economia neoclássica. Na sequência são apresentados os principais pontos que possibilitam a adoção da NEI e de seu ferramental metodológico nos estudos acerca do desenvolvimento rural. A última parte destina-se à apresentação dos componentes metodológicos e da proposta de adoção de um conceito de desenvolvimento rural à luz da NEI.

\section{O PROGRAMA DE PESQUISA DA NEI EM DOUGLASS NORTH}

Em boa parte, pode-se atribuir o sucesso da NEI (bem como o elevado número de críticos) ao ecletismo presente nas bases constitutivas de suas obras de referência, em especial aquelas produzidas por Douglass North. Ao longo de sua obra North deixa explícitas suas diversas influências teóricas. Há inúmeras menções a Smith, Marx, Hayek e Frank Knight. Em sua obra de 2005 North utiliza-se amplamente das ideias de Hayek, como o papel das crenças no processo de escolha, a noção de evolução cultural e a valorização da ciência cognitiva. North (2005a) utiliza a ideia de risco e incerteza (expressa na obra de Frank Knight), apresentando algumas modificações. Para Knight, o limite entre risco e incerteza é meramente probabilístico. Como apresenta North, porém, existem casos em que os agentes não possuem as informações precisas para suas tomadas de decisão; no entanto, em muitos desses casos os indivíduos estão constantemente buscando tornar o ambiente mais previsível, por meio do desenvolvimento de instituições.

\footnotetext{
5 Na verdade, a NEI reconhece o instrumental neoclássico apenas como explicação aos casos em que há alocação de recursos escassos e onde os custos de transação são zero. Tal posicionamento é explicitado em Coase (1937) e reafirmado Willianson (1989).

6 Para uma compreensão maior sobre o que trata um "programa de pesquisa", sob o ponto de vista epistemológico, ver Marconi e Lakatos (1999) e Blaug (1993).
} 
North, ainda, aponta para a existência de quatro elementos fundamentais para a compreensão da performance econômica, que segundo ele estão presentes na Riqueza das Nações, de Adam Smith, ${ }^{7}$ que são:

a. a transição da troca pessoal para a troca impessoal;

b. o processo de especialização e divisão do trabalho, demandando uma consequente especialização do conhecimento;

c. o funcionamento satisfatório dos mercados (sejam de produtos ou de fatores) depende da existência de uma certa estrutura de incentivos;

d. para o funcionamento pleno dos mercados há necessidade da presença do governo (NORTH, 2005b, p. 84-85).

No quesito governo (ou melhor, Estado), cabe lembrar que North utiliza-se do conceito de Estado hobbesiano, explícito na afirmação que o "Estado hobbesiano é uma extensão lógica do modelo neoclássico aplicado à teoria do Estado" (NORTH, 1981, p. 45). A utilização desse conceito apoia-se na ideia de que os agentes econômicos possuem interesse na restrição dos comportamentos, por meio de regras que normatizem a ação individual.

Também é possível verificar a influência de alguns sociólogos nos trabalhos de North, sobretudo do pensamento sociológico de Berger e Luckman (a partir de A Construção Social da Realidade), em especial na elaboração de seu conceito de ideologia. Outra contribuição sociológica à matriz conceitual de North origina-se dos conceitos de lei jurídica, convenção e costume, presentes na obra de Max Weber (Economia e Sociedade). Esses conceitos estão presentes na teoria de North sob a forma de restrições formais e informais, além de reforçarem a ideia de ideologia como restrição auxiliar. North (2005b) aponta, ainda, para a importante contribuição de Weber, em sua Ética Protestante, obra que destaca como a religião influencia eventos econômicos, no caso específico a emergência do capitalismo no mundo ocidental.

Para além de um mero autor neoclássico, como muitos dos críticos da NEI o apresentam, o estudo das influências teóricas de North nos possibilita observar como o autor propõe um diálogo com outras correntes de pensamento, procurando considerar temáticas não abordadas pelo mainstream.

Um dos pontos interessantes na análise das contribuições teóricas na construção da NEI (e na obra de North, especificamente) é a negligência em relação à tradição da Velha Economia Institucional, como muitos classificam a produção acadêmica de Veblen, Commons e Mitchell. ${ }^{8}$ Tanto North (1993a) como Coase (1991) qualificam essa abordagem como "ateórica". Em verdade, numa leitura atenta à obra de North, dificil-

\footnotetext{
Segundo North, tais elementos foram negligenciados pelos modernos neoclássicos exatamente por envolverem de forma explícita a análise institucional.

${ }^{8}$ O presente artigo não pretende realizar uma análise detida sobre a contribuição de tais autores. Aos que se interessarem, existem inúmeros trabalhos de referência nesse sentido, tais como Hodgson (1994; 2002), Conceição (2002; 2003), Furubotn; Richter (1997) e Ménard; Shirley (2005). Na verdade, esses três autores, que formam o "institucionalismo americano", não possuem uma visão idêntica sobre as instituições e seus papéis na sociedade. Entre Veblen e Commons, inclusive, há uma diferença no que tange ao conceito de Instituição: Veblen definirá instituição como hábitos mentais. Tais hábitos mentais surgem da relação evolutiva entre a avaliação social, a questão da subsistência e a necessidade de emulação. Commons definiu instituições como mecanismos através dos quais o controle coletivo é exercido, no intuito de resolver problemas oriundos da luta por recursos escassos (CAVALCANTE, 2014).
} 
mente se irá encontrar menção à contribuição de Veblen. ${ }^{9}$ Fica claro que a NEI não se apresenta como uma continuação do "Velho Institucionalismo", mas sim como abordagem que introduz contribuições no âmbito do programa de pesquisa neoclássico. Assim, o reconhecimento de que Veblen apresenta um programa de pesquisa alternativo explicaria, em parte, essa negligência de North e dos demais autores ligados à NEI. Ainda que não se vejam como correntes similares, no entanto, tanto os velhos como os novos institucionalistas possuem um ideário comum: construir teorias econômicas mais realistas.

Para Ménard e Shirley (2011), o paradigma neoclássico padrão vê o sistema econômico como o ajuste entre a oferta e a procura, em que a produção se liga ao consumo automaticamente, sob a coordenação de um mecanismo de preços. Os economistas neoclássicos tratam a empresa como uma caixa preta - uma função de produção que transforma entradas em saídas, respondendo às mudanças nos preços relativos e aos recursos disponíveis de forma a maximizar os lucros. Assim, ainda que existam pontos de convergência entre a NEI e os economistas neoclássicos, seu surgimento está fortemente marcado pelo pensamento heterodoxo e sua "... profunda insatisfação com o caminho trilhado pela escola neoclássica tradicional a partir do marginalismo" (PESSALI; FERNÁNDEZ, 1999, p. 1).

Para North (1993b), como já foi mencionado, este sistema funciona em determinadas situações hipotéticas e simplificadoras (escassez de recursos e custos de transação nulos). Algumas das hipóteses neoclássicas, no entanto, perturbaram os fundadores da $\mathrm{NEI}$, em especial os pressupostos de que a informação é perfeita; de que os indivíduos são racionais e maximizadores da riqueza; de que as preferências são estáveis; e de que as trocas são instantâneas e sem custos. Afora isso, existe uma ontologia neoclássica que a obra dos autores principais da NEI assume como possível de estabelecer um diálogo.

Que ontologia neoclássica seria essa, porém, que estaria presente nos pressupostos da NEI? Pode-se identificar alguns elementos definidores do programa de pesquisa neoclássico que estariam alinhados com a NEl, e em especial com as contribuições de North: (i) escolha sob escassez (individualismo); (ii) uso de modelos matemáticos; (iii) noções de equilíbrio e maximização. Vejamos como North estabelece os limites da sua crítica à tradição neoclássica.

A estrutura analítica é uma modificação da teoria neoclássica. O que retém é o suposto fundamental de escassez e, portanto, competição e as ferramentas analíticas da teoria microeconômica. $\mathrm{O}$ que modifica é o suposto de racionalidade. $\mathrm{O}$ que adiciona é a dimensão do tempo (NORTH, 1993b, p. 12).

Como se pode perceber pelas palavras do próprio Douglass North, este está de acordo com a economia neoclássica padrão, admitindo a existência de casos de escolha sob escassez. ${ }^{10}$ Essa é a definição do objeto da Economia, em uma ótica neoclássica. A

\footnotetext{
9 Somente em seu último livro, Understanding the Process of Economic Change, North faz uma breve referência à contribuição de Veblen (ainda que indireta) no que se refere a algumas questões consideradas pela economia evolucionária, sem, no entanto, aproximar os conceitos de Veblen ao seu esquema teórico.

${ }^{10}$ Importante mencionar que o conceito de "escassez" não nasceu em meio às escolas neoclássicas. Na verdade, o conceito é anterior, estando presente nas obras dos autores clássicos da economia política, entre eles Adam Smith, David Ricardo e Karl Marx.
} 
escolha é uma categoria relativa ao comportamento dos indivíduos; já a escassez refere-se à configuração das estruturas sociais. Se os recursos de um dado sistema econômico são escassos, a sua alocação se impõe como um problema teórico de estudo da Economia.

A ideia de recursos escassos remete ao fato de que os fatores de produção são dados e não podem ser empregados de forma ilimitada. Os recursos não podem ser criados. Dessa forma, recursos (escassos) só podem ser alocados ou realocados, nunca criados pelos agentes. Deste modo, considerando que as estruturas sociais são dadas, é a ação individual que tem poder de alocar e realocar os recursos em um sistema econômico, mediante suas escolhas. Tal fato é explicativo para se entender a ênfase neoclássica nas preferências individuais para explicar o sistema econômico. North deixa claro o foco no indivíduo, ao definir Economia como a teoria da escolha: "Economics is a theory of choice - so far so good" (NORTH, 2005b, p. 11). Ou seja, a investigação econômica preocupa-se em compreender como os indivíduos operam suas escolhas em um ambiente em que os recursos são escassos.

Outro elemento neoclássico que North entende deva ser mantido são as ferramentas microanalíticas (oriundas da teoria microeconômica padrão), que em linhas gerais podem ser compreendidas como a maximização sob restrição. Tais ferramentas analíticas dispõem que os indivíduos escolhem (maximizam) entre recursos escassos (restrição). A partir dessa construção, a teoria pode ser formalizada matematicamente. Seria possível pensar, a partir daí, em um esquema análogo entre a teoria do consumidor (com suas curvas de indiferença, refletindo as preferências individuais a serem otimizadas sob a restrição orçamentária) com a teoria institucionalista de North, em que as instituições são as restrições que direcionam os indivíduos na realização de suas escolhas. O próprio North argumenta que o conceito de instituições deve ser encarado como "complementar à abordagem da teoria da escolha da teoria econômica neoclássica" (NORTH, 1993b, p. 5).

Assim, ainda que se perceba a interação entre a NEI e as abordagens neoclássicas, é irrefutável o acréscimo teórico que os novos institucionalistas trazem à discussão econômica. Nesse sentido, Ménard e Shirley (2011, p. 2) afirmam que:

NIE arose in response to two puzzles not well explained by the standard neoclassical paradigm: the decision to make, to buy, or to look for alternative organizational arrangements and the explanation for why some countries are rich and some countries are poor.

Além das instituições, segundo North, outros dois elementos são importantes para a compreensão de um sistema econômico - organizações e indivíduos (por ele tratados como jogadores). Assim, para se caracterizar um sistema econômico, deve-se analisar as instituições presentes, bem como o papel que cumprem as organizações e os indivíduos nesse sistema.

North (e os demais autores da tríade novo institucionalista - Coase e Williamson) aponta também para a importância de se analisar os problemas de coordenação e cooperação entre os agentes econômicos. Segundo North, tal questão, diferentemente das 
instituições, já havia sido acolhida pelos neoclássicos no âmbito da teoria dos jogos. 0 autor sugere a revisão de alguns pontos do modelo neoclássico padrão, que supõe que indivíduos racionais, em condição de maximização, decidirão cooperar quando:

a. as interações forem repetidas;

b. existir informação completa sobre os outros jogadores;

c. presença de um número reduzido de jogadores (NORTH, 1993b, p. 12).

Para North, essa descrição de sistema econômico é muito distante da realidade, uma vez que as interações cotidianas podem não se repetir, além do fato de o ambiente de informação ser incompleto e de existir um grande número de jogadores.

Além disso, North adiciona aos problemas neoclássicos o viés temporal, o que permite - segundo o autor - considerar a evolução dos sistemas econômicos a partir de uma perspectiva dinâmica. Assim, a história assume um papel importante na matriz conceitual de North, ainda que seja adotada uma concepção particular de história - a cliometria (ou nova história econômica). Segundo North (1981) e North e Thomas (1973), a cliometria adotaria alguns supostos neoclássicos como individualismo metodológico, o do comportamento racional e o conceito de custo de oportunidade. $\mathrm{O}$ autor, no entanto, indica os limites do pensamento neoclássico padrão ao desenvolvimento da cliometria, qual seja, a não consideração dos custos de transação, a ausência de uma teoria do Estado (semelhante a public choice theory), bem como a inexistência de teorias que explicassem a alocação de recursos fora do sistema de mercado (utilizando, por exemplo, os direitos de propriedade e a ideologia).

Diante das questões levantadas pela NEI, e em especial por North, fica a pergunta: Como os indivíduos realizam suas escolhas num ambiente no qual a dimensão "tempo" está presente, a informação é incompleta, as interações na maioria das vezes não são repetidas e existe um grande número de indivíduos interagindo? No esquema neoclássico, entender como os indivíduos escolhem é fundamental para a compreensão da economia. E é nesse ponto (constituição do comportamento individual) que North sugere uma importante mudança no entendimento neoclássico. Para dar maior realismo à teoria da escolha, North rechaça o suposto de racionalidade instrumental. Os indivíduos são dotados de uma racionalidade incompleta, limitada, ou seja, os indivíduos não são capazes de processar toda informação disponível.

Para definir a distinção entre a racionalidade substantiva (ou instrumental) e o suposto de racionalidade limitada, North se remete a Herbert Simon, que define racionalidade limitada como o termo "usado para designar escolha racional que leva em consideração as limitações cognitivas do agente que toma decisões - limitações tanto do conhecimento quanto da capacidade computacional" (SIMON, 1979, p. 499). A questão central remete à quantidade de informação que o cérebro humano é capaz de processar. Indivíduos dotados de racionalidade limitada possuem uma capacidade computacional também limitada, não podendo processar toda informação necessária para sua maximização. Assim, indivíduos limitados cognitivamente não maximizam, mas chegam a um second best, ou a melhor alternativa possivel. Simon denominou essa modalidade de comportamento como satisficing. Para North, a presença das instituições está associada a um ambiente econômico no qual existam indivíduos limitados cognitivamente. 
Num mundo de racionalidade instrumental as instituições são desnecessárias; idéias, ideologias, mitos, dogmas não importam; e os mercados eficientes, tanto políticos quanto econômicos, caracterizam as sociedades. Mas no mundo real os atores possuem informação incompleta e capacidade computacional limitada para processar tal informação. Em conseqüência eles desenvolvem regras habituais e normas para estruturar a troca (NORTH, 1993b, p. 159-160).

Para Langlois (1986), a agenda de pesquisa da NEI pode ser descrita em quatro elementos:

a. Análise situacional - agentes são racionais, comportam-se razoavelmente no contexto da sua situação individual. A sua racionalidade é, no entanto, limitada e não necessita ser maximizada.

b. Instituições - existência de instituições sociais de vários tipos, e não agem apenas como limitações, mas também definem a situação individual do agente. Langlois aponta isso como "o duplo papel das instituições na análise econômica".

c. Explicações em conformidade com o princípio da "mão invisível" - fenômenos econômicos são concebidos como consequências não intencionais da interação humana.

d. Princípio da Composição - existem vários mecanismos e processos de seleção, seguindo o princípio da "mão invisível".

Para North, as instituições agem como um importante complemento cognitivo, redutor de incertezas, característica de um sistema econômico no qual os indivíduos possuem uma racionalidade limitada, as interações não são repetidas, a informação sobre os demais agentes não é completa e é grande o número de tais agentes.

O que se pode perceber é que North se apresenta de forma distinta no debate econômico. Fica clara a sua intenção de considerar as instituições, a história e o desenvolvimento econômico a partir das ferramentas analíticas próprias. Esse ponto é fundamental para compreender a NEI, seja nas obras de North, seja por intermédio de Coase e Williamson, e sua relação epistemológica com a economia neoclássica padrão.

Nesse sentido, a Figura 1 representa a forma como se pode compreender a relação entre a NEI e o pensamento neoclássico padrão. Observe-se que a representação contempla a relação, mas ao mesmo tempo expõe o fato de que a NEI se propõe a realizar análises mais ampliadas, inclusive adotando referenciais de outras ciências, como é o caso da Sociologia, do Direito e da Ciência Política. 
Figura 1 - Representação esquemática da relação NEI x Neoclássicos

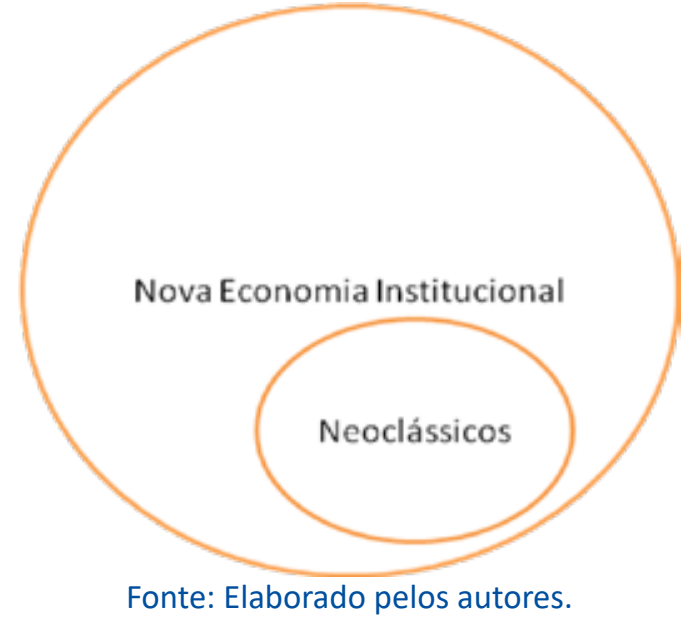

Os últimos 40 anos serviram para consolidar os pressupostos e contribuições da $\mathrm{NEI}$, mas também promoveram uma natural clivagem, em diferentes linhas de pesquisa. Ainda que haja uma diversidade de linhas de pesquisa, os trabalhos realizados pela NEI são mais complementares do que divergentes (FARINA; AZEVEDO; SAES, 1997). A maior diferença se dá nos níveis de análise.

Os dois principais níveis de análise adotados pela NEI são: a) a corrente da "estrutura de governança", cujo maior expoente é Oliver Williamson, constituindo a tônica a microanálise para soluções de questões da teoria da firma e organização industrial; b) a corrente do "ambiente institucional", cujo principal autor foi Douglass North, empregando um nível macroanalítico sobre a história das economias nacionais, o desenvolvimento e as transformações econômicas de longo prazo (SILVA, 2014, 2002). A Figura 2 faz uma representação esquemática dessa divisão.

Figura 2 - Principais Níveis e Linhas de Pesquisa da NEI

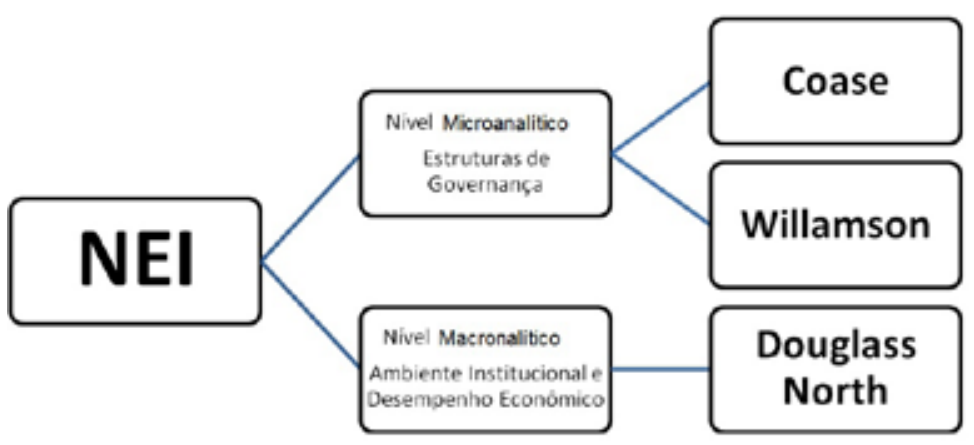

Fonte: Elaborado pelos autores.

Identificar a NEI (e o pensamento de North em particular) como sendo exclusivamente uma extensão do programa de pesquisa neoclássico é invalidar suas contribuições já apresentadas à discussão econômica. A questão relevante é em que medida North consegue tratar adequadamente as instituições, a história e o desenvolvimento econômico a partir das ferramentas analíticas da teoria microeconômica. Essa questão nos remete à apreciação dos fundamentos metodológicos do esquema conceitual de North. Também importa saber o quão adequada é a utilização da NEI para auxiliar nos debates sobre desenvolvimento rural, questão essa que será abordada na sequência. 


\section{A NEI COMO OPÇÃO METODOLÓGICA AO DEBATE DO DESENVOLVIMENTO RURAL}

Simultaneamente, é possível compreender que a NEI, mesmo guardando vinculações com a economia neoclássica, promove uma verdadeira ruptura com esta ${ }^{11}$ (CABALLERO; KINGSTON, 2005). Tal ruptura se dá pela introdução de algumas inovações aos seus pressupostos, que basicamente são:

a) a ideia de que as instituições importam, pois reduzem as incertezas e fornecem incentivos;

b) a existência de custos de transação;

c) a importância da história como elemento explicativo da trajetória econômica (path dependence);

d) as percepções e ideologias são derivadas das construções mentais dos agentes econômicos.

Ainda que se compreenda a dificuldade de conceituar "desenvolvimento rural", 12 pode-se perceber a adequação da NEI e suas principais possibilidades metodológicas e analíticas, que viabilizam uma leitura econômica do desenvolvimento rural:

a) preconiza um olhar multidisciplinar (integrando saberes da Economia, Sociologia, Geografia, Direito, etc.) sobre a temática do rural;

b) privilegia uma análise territorial em detrimento de uma abordagem meramente setorial;

c) evidencia o componente histórico como elemento explicativo na formação do território;

d) propõe uma análise endógena, sem desprestigiar a importância de elementos externos aos sistemas rurais;

e) considera o importante papel que cumpre o Estado para a consolidação do desenvolvimento rural.

Ploeg et al. (2000) destacam como traço fundamental do desenvolvimento rural a diversificação, com a criação de novos produtos, novos serviços e novos mercados. Fica claro como o estudo das instituições, e das consequentes mudanças institucionais, podem contribuir para o avanço das análises sobre o desenvolvimento rural. Esses novos produtos, serviços e mercados surgiram, em muitos casos, a partir de uma matriz institucional que os incentive.

Ao explicar aquilo que chamou de "abordagem institucional-cognitiva", North (1994) aponta para três aspectos que podem auxiliar na compreensão da NEI como elemento analítico do desenvolvimento rural:

a. a existência de um padrão desigual de desempenho econômico entre regiões (e países), o que implica privilegiar explicações endógenas e locais/regionais, para os fenômenos de desenvolvimento;

\footnotetext{
${ }^{11} \mathrm{O}$ próprio Douglass North, em um de seus últimos artigos, defende uma maior aproximação com a economia evolucionária e um gradual distanciamento dos pressupostos neoclássicos (NORTH, 2005a).

${ }^{12}$ Para maiores explicações sobre a evolução do conceito de Desenvolvimento Rural, ver Kageyama (2004; 2008).
} 
b. compreender que as economias sofrem com padrões de path dependence, ou seja, uma vez iniciada uma trajetória de crescimento (ou estagnação), tal processo tende a persistir no tempo;

c. considerar que existe uma interação entre as instituições que se estabelecem, as tecnologias que se adotam e as condições demográficas - e tais interações afetam diretamente os processos de mudança econômica das regiões.

Da mesma forma, como um dos elementos inovadores da NEI é a compreensão de que as relações contratuais entre os agentes são importantes fatores de análise do comportamento dos indivíduos, pode-se verificar aí outra vantagem do emprego dessa abordagem no estudo do desenvolvimento rural. Diversos estudos empíricos têm sido produzidos nos últimos anos, utilizando a NEI, e em especial a abordagem dos contratos, na análise de cadeias agroalimentares. ${ }^{13} \mathrm{~A}$ partir dos estudos das relações contratuais, a análise dos modelos de governança e cooperação é possível. Mais uma vez pode-se perceber a adequação do uso do ferramental analítico da NEI para esses propósitos.

Para Silva (2014, p. 131), "sem um processo de evolução das interações sociais com os recursos não há como pensar em desenvolvimento rural". A NEI permite a apreensão das relações humanas, entre si e com o meio em que vivem. $O$ institucionalismo permite um olhar a partir de múltiplas dimensões (política, social, geográfica, histórica e econômica), concebendo um rural igualmente múltiplo e complexo.

Cabe salientar que a NEI tem sido amplamente utilizada nos últimos anos em diferentes estudos empíricos, tanto na análise de aspectos pontuais de algumas cadeias agroindustriais (ALSTON, 2008; FERNÁNDEZ-OLMOS, 2008; MENDES; FIGUEIREDO; MICHELS, 2008), quanto em estudos mais amplos, nos quais a temática do desenvolvimento rural se apresenta de forma significativa (CABALLERO; KINGSTON, 2005; MATEI, 2015; AGNE, 2014; GAZOLLA, 2012; WEGREN, 2012; MELONI; SWINNEN, 2014). A partir desta justificativa do uso da NEI em estudos de desenvolvimento rural propõe-se uma estrutura metodológica que embase a compreensão do papel das instituições sobre as transformações recentes da vitivinicultura da Serra Gaúcha.

\section{Instituições e Desenvolvimento Rural na Vitivinicultura da Serra Gaúcha}

O presente artigo pretende discutir a possibilidade de se compreender o desenvolvimento rural sob uma perspectiva institucional, pautada nas contribuições da Nova Economia Institucional (NEI). A intenção é incorporar uma análise empírica sobre a aplicação dos conceitos aqui expostos, observando o caso da vitivinicultura da Serra Gaúcha e as transformações ocorridas em sua matriz institucional nos últimos 30 anos.

Em verdade, a própria discussão e conceitos sobre desenvolvimento rural mudaram muito nesse período. Como bem apresenta Schneider (2010), passou-se de um enfoque majoritariamente baseado na intervenção estatal no campo, predominante até o período da redemocratização do país, para uma gradativa mudança de orientação, que chega até os dias atuais. As mudanças conceituais que se sucederam dinamizaram a discussão do desenvolvimento rural, incluindo no centro dos debates as "políticas go-

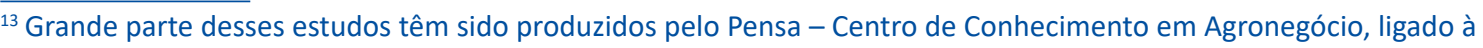
Universidade de São Paulo (USP).
} 
vernamentais direcionadas para a reforma agrária, o crédito para agricultura familiar, o apoio aos territórios rurais, o estímulo a ações afirmativas para mulheres, jovens, aposentados e negros" (SCHNEIDER, 2010, p. 512). Coincide que o período em que Schneider (2010) aponta para uma mudança na interpretação sobre o desenvolvimento rural no Brasil seja o mesmo das principais alterações na vitivinicultura brasileira, em especial na Serra Gaúcha, ou seja, a partir dos anos 90. Schneider (2010) classifica tais mudanças no entendimento sobre desenvolvimento rural no Brasil, nos últimos anos, em quatro grandes abordagens.

A primeira abordagem é aquela que denomina "instituições, inovação e sustentabilidade". Os principais expoentes dessa abordagem são José Eli da Veiga e Ricardo Abramovay. O ponto de consenso para ambos é a valorização da agricultura familiar e o reconhecimento de seu potencial dinamizador das economias. Tais autores (e seus seguidores), em linhas gerais,

sustentam o argumento de que a capacidade de inovação dos agricultores familiares e sua interação com as instituições locais são fundamentais para que possam ampliar a geração e agregação de valor, assim como reduzir custos de transação e estimular economias de escopo (SCHNEIDER, 2010, p. 519).

A segunda linha que se origina dos debates sobre desenvolvimento rural a partir da década de 90 é a abordagem do "novo rural brasileiro", cujo principal propagador é o ex-professor da Unicamp José Graziano da Silva. Para este autor (2001, p. 37), o "novo rural brasileiro decorre do próprio processo de modernização conservadora da base tecnológica da agropecuária". Esse novo rural seria composto por três grupos de atividades: uma agropecuária moderna (agronegócio) ligada às commodities e às agroindústrias; um conjunto de atividades não agrícolas ligadas à moradia, ao lazer e a várias atividades industriais e de prestação de serviços e um conjunto de novas atividades agropecuárias, impulsionadas por nichos de mercado (GRAZIANO DA SILVA, 2001).

A terceira vertente de estudos sobre o desenvolvimento rural seria aquela que centra a sua agenda temática sobre os condicionantes e as potencialidades dos processos de mudança social no meio rural, a partir da análise da tradição política de tipo tradicional e patriarcal, que em muitos casos impede não só as transformações estruturais, mas, principalmente, as mudanças socioculturais. Os principais autores dessa vertente são José de Souza Martins e Zander Navarro. Para estes autores, no Brasil, o desenvolvimento dos espaços rurais passa, necessariamente, pela "promoção de processos radicais de democratização, que pudessem libertar os indivíduos e grupos sociais da tutela e controle exercido pelas elites e pelos mediadores (agentes da Igreja, do Estado, dos partidos políticos, dos movimentos sociais)" (SCHNEIDER, 2010, p. 523).

A última abordagem, segundo Schneider (2010), trata de focalizar o agronegócio e as cadeias agroalimentares sob uma perspectiva que, em geral, difere da teoria econômica convencional (mainstream). Entre os principais autores dessa abordagem estão John Wilkinson e Mário Batalha. A tônica de seus trabalhos consiste em analisar as formas de integração dos pequenos produtores nas cadeias agroindustriais ou agroalimentares, dando uma especial atenção aos aspectos sociais deste processo. Como salienta Schneider (2010), os autores que se identificam com essa abordagem não se restringem a analisar apenas as formas de gestão, tomadas de decisão, formas de inovação, acesso 
a mercados e comercialização, mas buscam compreender em que condições os pequenos produtores e suas organizações podem fazer frente aos desafios da forma como o capitalismo opera na agricultura e na produção de alimentos.

O "enfoque agroindustrial", segundo Wilkinson (2000, 2008), tem por foco compreender quais são as possibilidades para a agricultura familiar em um momento de transformação do capitalismo na atualidade. Para este autor, "a vontade do consumidor passará a orientar a organização da produção e os tipos de produtos" (WILKINSON, 2008, p. 15).

O presente artigo possui um alinhamento teórico com as abordagens "instituições, inovação e sustentabilidade" e com o "enfoque agroindustrial". Esse alinhamento não desmerece os avanços particulares que as demais abordagens trouxeram para o debate do desenvolvimento rural no Brasil, no entanto a proximidade com alguns conceitos usuais para tais abordagens é que justifica tal associação, em especial a importância dada a determinados conceitos, tais como instituições, inovação, território e cooperação. Tais conceitos são fundamentais, como será apresentado, para compreender o modelo de desenvolvimento institucional rural aplicado à vitivinicultura da Serra Gaúcha.

\section{DESENVOLVIMENTO INSTITUCIONAL RURAL - PROPOSTA ANALÍTICA}

O esforço metodológico desenvolvido até aqui possibilita a constituição da proposta teórica do Desenvolvimento Institucional Rural (DIR). As concepções presentes neste artigo consideram as instituições sob a perspectiva da NEI. A ideia central é a que está presente nas diversas obras de Douglass North, ${ }^{14}$ ou seja:

As instituições são as construções humanamente concebidas que estruturam a interação humana. Elas são feitas de restrições formais (regras, leis, constituições), de restrições informais (normas de comportamento, convenções e códigos de conduta autoimpostos) e de suas respectivas características impositivas (NORTH, 2010, p. 16).

Para North, analisar o papel das instituições é fundamental para compreender o desempenho econômico e social de uma determinada sociedade, ao longo do tempo. Nesse sentido, além de ter o conceito de "instituição" como central, também importa considerar a existência de duas noções igualmente fundamentais: a adoção de uma abordagem histórica e a noção de território.

A abordagem histórica é um dos elementos centrais na proposta analítica da NEI. Está consolidada nas obras de Douglass North, desde seu primeiro trabalho em 1961 (Economic Growth of the US 1790 - 1860). Ao longo do tempo, se existe algo que está continuamente presente em sua produção intelectual é a importância que North dá aos processos históricos para compreensão dos fenômenos sociais e econômicos. Isso porque a história (ou o tempo, como apresenta algumas vezes) afeta a constituição da aprendizagem, individual e coletiva, em uma sociedade. "Tempo, nesse contexto, implica não somente experiências atuais e aprendizagem, mas também a experiência acumulada nas gerações passadas, que se materializa na cultura" (NORTH, 2010, p. 23). E é justamente essa cultura que fornece o suporte para o processo de path dependence, ou seja, a forma como as situações e decisões do passado influenciam as decisões do presente e do futuro. "Sociedades que ficam 'presas' incorporam sistemas de crenças e instituições que não

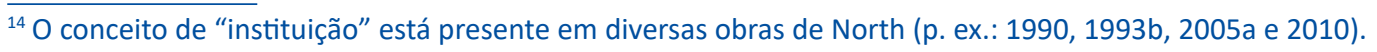


conseguem enfrentar e resolver os novos problemas da complexidade social" (NORTH, 2010, p. 23). Disso se depreende que nenhum estudo que pretenda entender o papel das instituições em uma sociedade pode ocorrer apartado de uma percepção histórica.

O outro ponto relevante é ter clara a noção de território. $O$ uso das abordagens territoriais apresenta inúmeras vantagens e avanços (ABRAMOVAY, 2006; COURLET, 2008; PECQUEUR, 2000, 2006; RAMIREZ, 2008). Para Abramovay (2006), entre os principais avanços da noção de território, podem ser citados:

a) abandono do horizonte estritamente setorial;

b) impedimento à confusão entre crescimento econômico e o processo de desenvolvimento (e isso exige que se incorpore uma análise institucional); ${ }^{15}$

c) priorização do estudo empírico dos atores e de suas organizações;

d) possibilidade de um estudo da organização produtiva e das suas relações com os sistemas sociais e ecológicos.

A abordagem territorial tem sido amplamente utilizada tanto no ambiente acadêmico quanto no âmbito das políticas públicas (FREITAS, 2016). As questões territoriais e a sua temporalidade são elementos fundamentais para compreender o desenvolvimento econômico local/regional. Isso porque o território é um processo histórico e dinâmico. Como lembra Paulo Alexandre Neto:

o tempo do território é o tempo dos agentes econômicos que aí estão localizados. E a forma como perduram, se multiplicam e se fortalecem com a passagem do tempo determina a qualidade e o nível de desenvolvimento do território em cada momento do tempo (2006, p. 17).

Assim, esses elementos (abordagem histórica e territorial) estão na base da composição do modelo de desenvolvimento rural com enfoque nas instituições. A relação entre eles está expressa na Figura 3, que representa a forma de interação entre eles.

Figura 3 - Relação entre abordagem territorial e histórica na construção do modelo de Desenvolvimento Institucional Rural

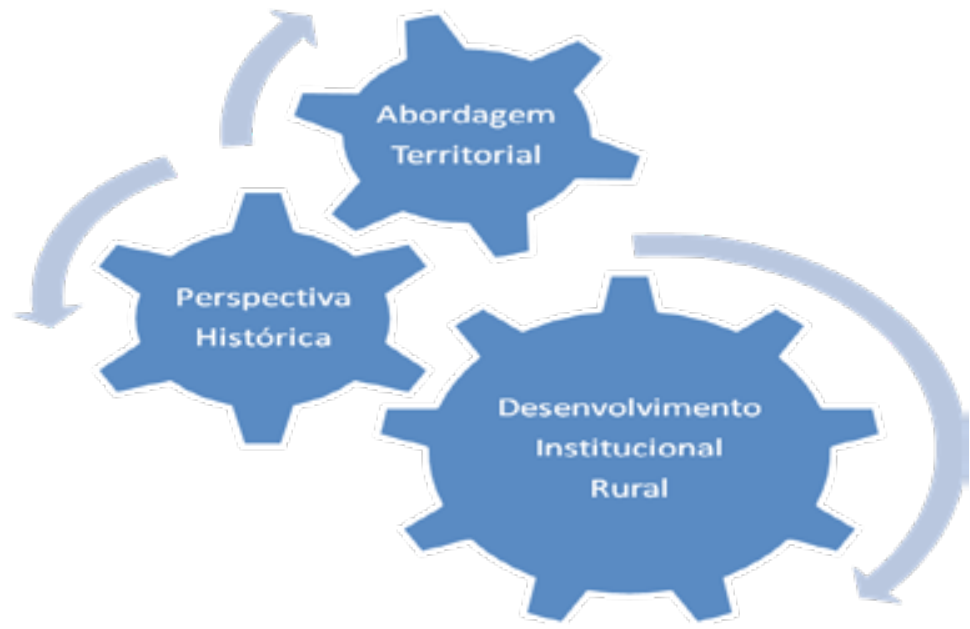

Fonte: Elaborado pelos autores.

15 "Não se trata apenas de examinar como se formam e como se podem reduzir os custos de transação, mas abordá-los desde um ângulo histórico e da influência que sobre eles exercem as forças sociais que as constituem" (ABRAMOVAY, 2006, p. 52). 
A partir desse entendimento pode-se compreender o conceito de Desenvolvimento Institucional Rural como sendo: o conjunto de arranjos dos ambientes institucional, tecnológico, organizacional e competitivo, no âmbito do rural, que ao longo do tempo, conformam o comportamento dos agentes, por meio de incentivos à atividade produti$v a$, à redução dos custos de transação e ao fortalecimento do território.

O conceito supracitado trata de entender o desenvolvimento rural de forma mais ampla do que apenas um olhar econômico sobre a produção em ambientes rurais. Envolve, sim, a percepção de múltiplas dimensões: territorial, econômica (competitiva), tecnológico-produtiva, institucional e organizacional. Nesse sentido, a proposta está de acordo com as indicações de Kageyama (2008) para compreensão do desenvolvimento rural, em especial para o caso brasileiro. A proposta também encontra respaldo em vários pontos do pensamento de Veiga (2001), em especial no que menciona que as estratégias de desenvolvimento rural necessitam uma percepção acurada para a diversificação das economias locais, na ampliação do olhar setorial e para uma análise sobre a pluriatividade das famílias rurais, com vistas à geração de renda e retenção/absorção da mão de obra local.

Da mesma forma, importa frisar a proximidade conceitual com Ploeg et al. (2000, p. 393) acerca do desenvolvimento de espaços rurais, em especial com o entendimento de que se trata de um "processo multi-nível, multi-atores e multifacetado". Tal compreensão é necessária, pois entende-se que o processo de desenvolvimento rural é complexo, sob o ponto de vista institucional, dependendo de múltiplos atores, envolvidos mutuamente, formando redes. De igual modo, as novas práticas rurais, tais como a conservação da natureza, o turismo rural, a agricultura orgânica, a produção de especialidades regionais, fazem com que o processo de desenvolvimento rural torne-se cada vez mais amplo e complexo. Em síntese, a proposta resultante do presente estudo pode ser sintetizada na Figura 4.

Figura 4 - Desenvolvimento Institucional Rural (Modelo Analítico)

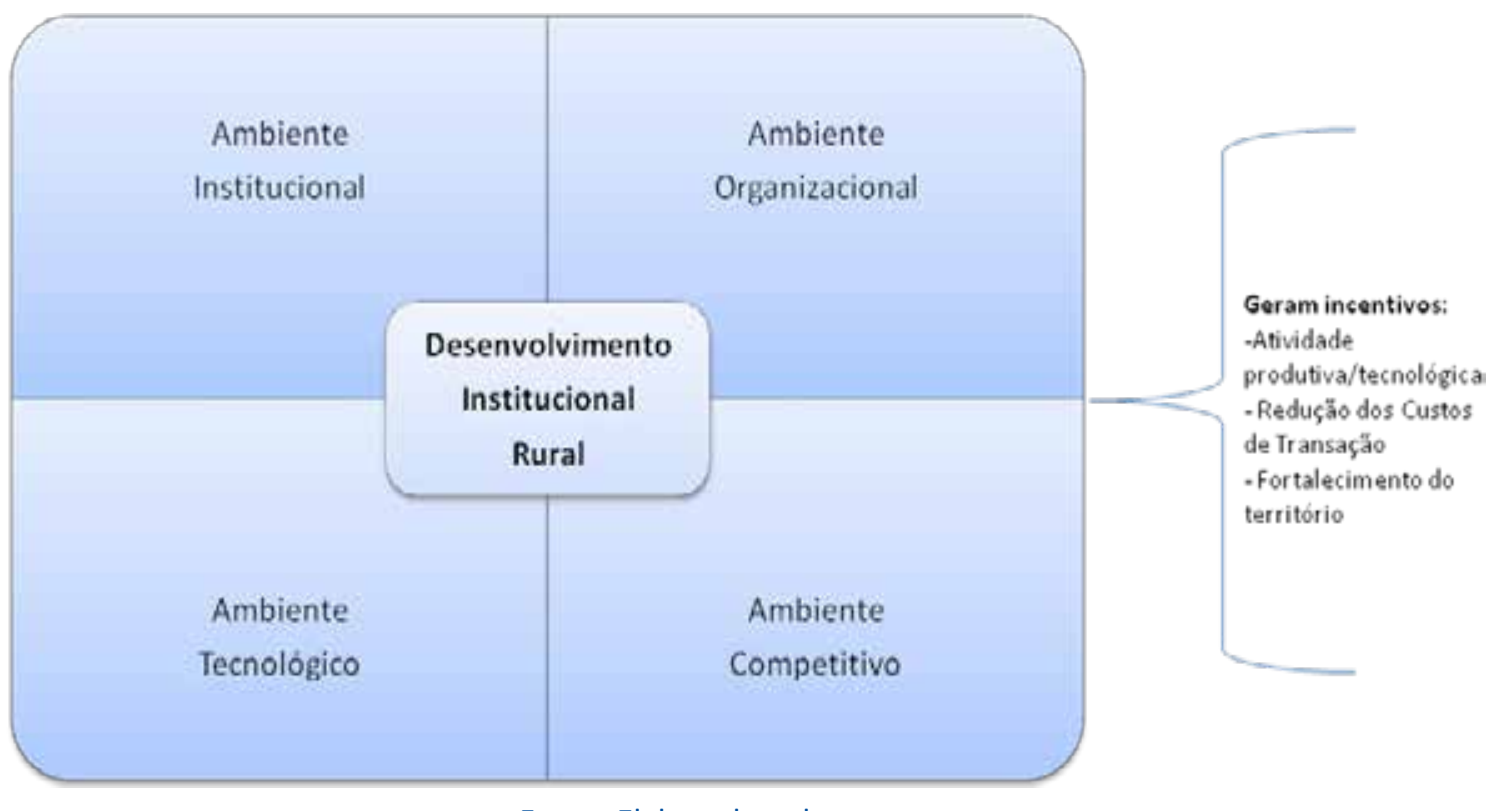

Fonte: Elaborado pelos autores. 
Uma aplicação desse modelo analítico foi desenvolvido por Farias (2016), que buscou apresentar as principais transformações ocorridas na vitivinicultura da Serra Gaúcha, nos ambientes institucional, tecnológico, organizacional e competitivo nos últimos 30 anos. Uma das questões centrais do trabalho de Farias (2016) era responder se as instituições podem melhorar o desenvolvimento rural. 0 estudo fornece indícios para uma resposta positiva: as instituições tiveram um papel preponderante no desenvolvimento rural da vitivinicultura da Serra Gaúcha. E essa conclusão estende-se em um horizonte temporal mais amplo, para além dos últimos 30 anos. Dessa forma, o autor considera que as instituições, ao longo do tempo, não somente promoveram a melhora do desenvolvimento rural da região, como também afetaram a conformação da própria cadeia produtiva.

Segundo Farias (2016), as instituições criadas a partir do início dos anos 90, e que continuam em atividade até a presente data, ajudaram, basicamente na promoção da ação coletiva dos agentes econômicos da cadeia; melhoraram as condições de produtividade e de competitividade; têm buscado desenvolver estratégias que privilegiem as economias de escopo, sobretudo entre os pequenos produtores; têm, a partir de programas e projetos específicos, reduzido os custos de transação entre os agentes da cadeia, principalmente porque têm auxiliado a melhorar a comunicação entre eles, bem como a qualidade da informação produzida. ${ }^{16}$

A ampliação das pesquisas empíricas no campo da análise do desenvolvimento institucional rural poderá confirmar se o modelo aqui apresentado pode ser empregado na compreensão de outros sistemas agroindustriais. Por fim, a realização de estudos empíricos que consideram a influência das instituições informais torna-se indispensável, não apenas porque possibilitará a ampliação desse conhecimento (ainda restrito), mas também porque promoverá, necessariamente, um aprofundamento do conhecimento interdisciplinar, fundamental para as análises do desenvolvimento rural.

\section{REFERÊNCIAS}

ABRAMOVAY, R. Para una teoría de los estudios territoriales. In: MANZANAL, Mabel; NEIMAN, Guilhermo; LATTUADA, Mario (org.). Desarrollo rural: organizaciones, instituciones y territórios. Buenos Aires: CICCUS, 2006. p. 51-70.

AGNE, C. L. Mudanças institucionais na agricultura familiar: as políticas locais e as políticas públicas nas trajetórias das famílias nas atividades de processamento de alimentos no Rio Grande do Sul. 2014. Tese (Doutorado em Desenvolvimento Rural) - Faculdade de Ciências Econômicas, Universidade Federal do Rio Grande do Sul, Porto Alegre, 2014.

AGUILAR FILHO, H. A. O institucionalismo de Douglas North e as interpretações weberianas do atraso brasileiro. 2009. Tese (Doutorado em Economia do Desenvolvimento) - Faculdade de Ciências Econômicas, Universidade Federal do Rio Grande do Sul, Porto Alegre, 2009.

ALSTON, L. The "Case" for case studies in new institutional economics. In: BROUSSEAU, E.; GLACHANT, J. M. New institutional economics: a guidebook. New York: Cambridge University Press, 2008. p. 103-121.

AYALA ESPINO, J. Instituciones para mejorar el desarrollo: un nuevo pacto social para el crecimiento y el bienestar. México: FCE, 2003.

BLAUG, M. Metodologia da economia. 2. ed. rev. São Paulo: Edusp, 1993.

CABALLERO, G.; KINGSTON, C. Capital social e instituciones en el proceso de cambio económico. Ekonomiaz, Vitoria-Gasteiz, n. 59, p. 72-93, 2005.

\footnotetext{
${ }^{16}$ Como menciona Ayala Espino (2003), as soluções institucionais aos problemas de custos de transação dificilmente podem ser genéricas. Devem, em realidade, ser cuidadosamente atendidas com propostas ad hoc.
} 
CAVALCANTE, C. M. Análise metodológica da economia institucional. 2007. Dissertação (Mestrado em Economia) - Departamento de Economia, Universidade Federal Fluminense, Niterói, 2007.

CAVALCANTE, C. M. A Economia Institucional e as três dimensões das instituições. Revista de Economia Política Contemporânea, Rio de Janeiro, v. 18, n. 3, p. 373-392, 2014.

CHANG, H. J. La relación entre las instituciones y el desarrollo econômico: problemas teóricos claves. Revista de Economía Institucional, Bogotá, v. 8, n. 14, p. 125-136, 2006.

CHANG, H. J. Chutando a escada: a estratégia do desenvolvimento em perspectiva histórica. São Paulo: Editora Unesp, 2004.

COASE, R. H. The nature of the firm. Economica, London, v. 4, n. 16, p. 386-405, nov. 1937.

COASE, R. H. The problem of social cost. Journal of Law and Economics, Chicago, v. 3, n. 1, p. 1-44, 1960.

COASE, R. H. Prize lecture: the institutional structure of production. Estocolmo: Nobel Prize Org., 1991. Disponível em: http://www.nobelprize.org/nobel_prizes/economic-sciences/laureates/1991/coase-lecture.html. Acesso em: 12 out. 2016.

CONCEIÇÃO, O. Os institucionalistas e a constituição de uma teoria econômica das instituições. In: ENCONTRO DE ECONOMISTAS DA LÍNGUA PORTUGUESA, 5., 2003, Recife. Anais [...]. Recife: [s.n.], 2003. Disponível em: www.race.nuca.ie.ufrj.br. Acesso em: 23 out 2016.

CONCEIÇÃO, O. O conceito de instituição nas modernas abordagens institucionalistas. Revista de Economia Contemporânea, Rio de Janeiro, v. 6, n. 2, p. 119-146, jul./dez. 2002.

COURLET, C. L. Èconomie territoriale. 2. ed. Grenoble: PUG, 2008.

FARIAS, C. V. S. O papel das instituições na formação e transformação da vitivinicultura da Serra Gaúcha: possibilidades de interpretações do desenvolvimento rural pela nova economia institucional. 2016, 280p. Tese (Doutorado) - UFRGS; FCE; PGDR, Porto Alegre, 2016.

FARINA, E. M. M. Q.; AZEVEDO, P. F.; SAES, M. S. M. Competitividade: mercado, Estado e organizações. São Paulo: Editora Singular, 1997.

FERNÁNDEZ-OLMOS, M. Why use contracts in viticulture? Journal of Wine Research, London, v. 19, n. 2, p. 81-93, 2008.

FREITAS, A. F. Por uma abordagem relacional do desenvolvimento territorial rural. RESR, Piracicaba, SP, vol. 54, n. 4, p. 667-690, out./dez. 2016.

FURUBOTN, E. G.; RICHTER, R. Institutions and Economic Theory: an introduction to and assessment of the new institutional economics. Michigan: University of Michigan Press, 1997.

GAZOLLA, M. Conhecimentos, produção de novidades e ações institucionais: cadeias curtas das agroindústrias familiares. 2012. Tese (Doutorado em Desenvolvimento Rural) - Faculdade de Ciências Econômicas, Universidade Federal do Rio Grande do Sul, Porto Alegre, 2012.

GRAZIANO DA SILVA, J. A modernização dolorosa: estrutura agrária, fronteira agrícola e trabalhadores rurais no Brasil. Rio de Janeiro: Zahar Editores, 1982.

GRAZIANO DA SILVA, J. Velhos e novos mitos do rural brasileiro. Estudos Avançados, São Paulo, v. 15, n. 43, p. 37-50, 2001.

HODGSON, G. M. The return of institutional economics. In: SMELSER, N. J.; SWEDBERG, R. (ed.). The handbook of economic sociology. New York: Princeton University Press; Princeton \& Russel Sage Foundation, 1994.

HODGSON, G. M. The Evolution of Institutions: An Agenda for Future Theoretical Research. Constitutional Political Economy, Norwell, v. 13, .n. 2, p. 111-127, june 2002.

KAGEYAMA, A. Mudanças no trabalho rural no Brasil, 1992-2002. Agricultura em São Paulo, São Paulo, v. 51, t. 2, p. 71-84, 2004.

KAGEYAMA, A. Desenvolvimento rural: conceitos e aplicações ao caso brasileiro. Porto Alegre: UFRGS; PGDR, 2008.

LANGLOIS, R. Rationality, Institutions, and Explanation. In: LANGLOIS, R. N. (ed.). Economics as a Process: Essays in the New Institutional Economics. New York: Cambridge University Press, 1986.

LANGLOIS, R. N.; COSGEL, M. M. Frank Knight on risk, uncertainty, and the firm: a new interpretation. Economic Inquiry, Long Beach, v. 31, p. 456-465, jul. 1993.

MARCONI, M. A.; LAKATOS, E. M. Técnicas de pesquisa: planejamento e execução de pesquisas, amostragens e técnicas de pesquisas, elaboração, análise e interpretação de dados. 4. ed. São Paulo: Atlas, 1999.

MATEI, A. P. Os processos de inovação e as interações nas agroindústrias familiares em regiões do Brasil e da Itália. 2015. Tese (Doutorado em Desenvolvimento Rural) - Faculdade de Ciências Econômicas, Universidade Federal do Rio Grande do Sul, Porto Alegre, 2015. 
MELONI, G.; SWINNEN, J. F. M. The political economy of european wine regulations. Journal of Wine Economics, New York, v. 8, n.3, p. 244-284, 2003.

MÉNARD, C. Enjeux d'eau: la dimension institutionnelle. Tiers Monde, Paris, v. 42, p. 259-274, 2001.

MÉNARD, C.; SHIRLEY, M. (ed.). Handbook of new institutional economics. Dordrecht: Springer, 2005.

MÉNARD, C.; SHIRLEY, M. (ed.). The contribution of Douglas North to new institutional economics. Cambridge: Cambridge University Press, 2011.

MENDES, K.; FIGUEIREDO, J. C.; MICHELS, I. L. A nova economia institucional e sua aplicação no estudo do agronegócio brasileiro. Revista de Economia e Agronegocio=Brazilian Review of Economics and Agribusiness, Viçosa, v. 6, n. 3, p. 309-342, 2008.

NETO, P. A. Território e desenvolvimento econômico. Lisboa: Instituto Piaget, 2006.

NORTH, D. Economic performance through time. In: ALSTON, L. et al. (ed.). Empiric studies in institutional change. Cambridge: Cambridge University Press, 1990.

NORTH, D. Structure and Change in Economic History. New York: W.W. Norton and Company, 1981.

NORTH, D. Economic performance through tame. American Economic Review, Nashville, v. 84, n. 3, p. 359-368, jun. 1994.

NORTH, D. Prize Lecture: Economic performance through time. Estocolmo: Nobel Prize Org., 1993a. Disponível em: http://www.nobelprize.org/nobel_prizes/economic-sciences/laureates/1993/north-lecture. html. Acesso em: 18 mar. 2017.

NORTH, D. Instituciones, cambio institucional y desempeño económico. México: Fondo de Cultura Económica, 1993b.

NORTH, D. Institutions and the performance of economies over time. In: MÉNARD, C.; SHIRLEY, M. M. (ed.). Handbook of New Institutional Economics. New York: Springer, 2005a. p. 21-30.

NORTH, D. Understanding the process of institutional change. Princeton: Princeton University Press. 2005b.

NORTH, D. Custos de transação, instituições e desempenho econômico. 3. ed. Rio de Janeiro: Instituto Liberal, 2006.

NORTH, D. Economics and Cognitive Science. Procedia Social and Behavioral Sciences, Amsterdan, v. 2, p. 7.371-1.376, 2010.

NORTH, D.; THOMAS, R. P. The rise of the western world: a new economic history. Cambridge: Cambridge Press, 1973.

PECQUEUR, B. O desenvolvimento territorial: uma nova abordagem dos processos de desenvolvimento para as economias do sul. Raízes, Florianópolis, v. 24, n. 1-2, p. 10-22, jan./dez. 2005.

PECQUEUR, B. Qualidade e desenvolvimento territorial: a hipótese da cesta de bens e de serviços territorializados. Eisforia, Florianópolis, v. 4, p. 81-103, 2006.

PECQUEUR, B. Le développement local. Paris: Syros, 2000.

PEREIRA, F. A. M. A evolução da teoria institucional nos estudos organizacionais: um campo de pesquisa a ser explorado. Organizações em Contexto, São Bernardo do Campo, v. 8, n. 16, p. 275-295, 2012.

PESSALI, H. F.; FERNÁNDEZ, R. G. Institutional economics at the micro level: what transaction costs theory should learn from original Institutionalism. Journal of Economic Issues, Sacramento, v. 33, n. 2, p. 265273, 1999.

PLOEG, J. D. Van Der et al. Rural development: from practices and policies towards theory. Sociologia Ruralis, Assen, v. 40, n. 4, p. 391-408, out. 2000.

RAMIREZ, E. La identidad como elemento dinamizador de la economía territorial. Opera, London, n. 7, p. 55-67, 2008.

SCHNEIDER, S. Situando o desenvolvimento rural no Brasil: o contexto e as questões em debate. Revista de Economia Politica - Brazilian Journal of Political Economy, São Paulo, v. 30, n. 3, p. 511-531, 2010.

SILVA, L. X. Análise do complexo agroindustrial fumageiro sul-brasileiro sob o enfoque da economia dos custos de transação. 2002. Tese (Doutorado em Economia) - Faculdade de Ciências Econômicas, Universidade Federal do Rio Grande do Sul, Porto Alegre, 2002.

SILVA, L. X. Instituições e desempenho: interpretações para o entendimento do desenvolvimento rural. In: CONTERATO, M. A.; RADOMSKY, G. F. W.; SCHNEIDER, S. (org.). Pesquisa em desenvolvimento rural: aportes teóricos e proposições metodológicas. Porto Alegre: UFRGS, 2014. v. 1.

SIMON, H. A. Comportamento administrativo: estudo dos processos decisórios nas organizações administrativas. 3. ed. Rio de Janeiro: Fundação Getúlio Vargas, 1979. 
THERET, B. As instituições entre as estruturas e as ações. Lua Nova: cultura e política. São Paulo, n. 58, p. 225-254, 2003. Disponível: http://www.scielo.br/scielo.php?script=sci_serial\&pid=01026445\&lng=pt\&nr$\mathrm{m}=$ iso\&rep. Acesso em: 29 out 2016.

VEIGA, J. E. O Brasil rural precisa de uma estratégia de desenvolvimento. Brasília: MDA; CNDRS; NEAD, 2001.

VEIGA, J. E. Destinos da ruralidade no processo de globalização. Estudos Avançados, São Paulo, v. 18, n. 51, maio/ago. 2004.

WEGREN, S. K. The Impact of WTO Accession on Russia's Agriculture. Post-Soviet Affairs, Silver Spring, v. 28, n. 3, p. 296-318, 2012.

WILLIAMSON, O. E. Las Instituciones Económicas del Capitalismo. Ciudad del Mexico: Fondo de Cultura Económica, 1989.

WILKINSON, J. O Estado, agricultura e a pequena produção. São Paulo: Hucitec, 1985.

WILKINSON, J. Distintos enfoques e debates sobre a produção familiar no meio rural. Agroecologia e Desenvolvimento Rural Sustentável, Porto Alegre, v. 1, n. 3, p. 11-19, 2000.

WILKINSON, J. Mercados, redes e valores: o novo mundo da agricultura familiar. Porto Alegre: UFRGS; PGDR, 2008. 213p. 